mixed success operationally. The German air force seems to have had a particularly unhappy time with it. Unless this new project comes off, few of the aircraft industries involved in the six countries can have a very good chance of survival. West Germany's industry is perhaps the weakest of all, but despite this there were reports last week that the West German Government was keen to gain design leadership of the project.

Britain's bargaining position in the talks, which are likely to last about six months, will probably be based on two arguments. On the one hand, it is likely to bc argued that alone among the six, Britain has the capacity, though not perhaps the inclination, to go it alone. On the other hand, Britain is likely to point to groundwork already carried out by the British Aircraft Corporation, which has been putting together design details for a variable-geometry aircraft. (It is not in fact clear yet whether the British Government is basing discussions exclusively on this design, or would be willing to consider something else.) And although Britain's withdrawal from the Far East may make it easier to bring British requirements into line with those of Europe, there are still likely to be differences of opinion over specifications. The estimates of possible sales of 1,000 aircraft, worth $£ 2,000$ million, are therefore premature.

Collaboration on this scale always increases costs. According to $\mathrm{Mr}$ Healey, the British Minister of Defence, a two way collaboration increases costs by about 20 per cent. A six-way collaboration would doubtless be very much worse but, even so, if it is assumed that research and development costs are divided equally, the cost to each country of developing the aircraft collaboratively would be about a quarter of the cost of going it alone. This is a compelling inducement for the negotiators to reach reasonable terms.

\section{No Prisons for Zanzibar}

WESTERN penologists may envy the freedom of other countries to conduct experiments in penal reform. Zanzibar is to abolish courts of law and prison sentences for all crimes other than murder and robbery with violence. The governing council of the island hopes to eliminate prisons altogether, and in future offenders will be sent to penal reform institutions for five years where they will be taught a trade.

The Tanzanian High Commission in London has not yet received details of these reforms, so it is hard to assess their significance. It is not known what rights of defence will be accorded to those accused of crimes. And though it may be a fine ideal to abolish prisons, "penal reform institutions" could be different only in name.

Announcing the reforms on July 14 the President of Zanzibar said that poverty was the principal determinant of crime and that the government would concentrate on raising the standard of living. Although poverty is undoubtedly related to crime, it seems to be relative rather than absolute indigence that encourages antisocial activity. The Zanzibaris may be naive in supposing that increased wealth will diminish crime, or that offenders will be reformed by the acquisition of an honest trade. But there is much to be gained from experimenting with the conventional penal system; prisons are expensive, degrading and lamentably inefficient in performing their stated aims. The Home Office is unable to supply recent figures but more than half the British prison population of 1961 had been in prison before. Britain now spends some $£ 30$ million a year on the prison service; an average weekly cost of $£ 14$ per prisoner. If more than half the people who have received this expensive treatment can be expected to commit further crimes on their release, it is hard to be satisfied that prison either benefits the prisoner or protects society.

Since 1948 it has been judicial policy in Britain to send increasingly fewer categories of offender to prison. The Zanzibaris have apparently taken this policy to its logical conclusion. The results of their experiment, if it has been properly set up, will be watched with interest.

\section{Weeds Underwater}

MACHINERY, chemicals and biological control are being used on an increasingly large scale to clear weeds from British lakes, streams and ditches-a job traditionally carried out by unskilled labourers. In a recent bulletin, Mr T. O. Robson of the Agricultural Research Council's Weed Research Organization at Oxford describes the basic principles of weed control and summarizes new methods which have either already been shown to be successful, or which are still at the experimental stage (The Control of Aquatic Weeds, H.MSO, 5s. 9d.).

Although aquatic weeds may cause flooding and silting and also interfere with recreational activities such as fishing, boating and bathing, they also aerate water, provide shelter for smaller animals, consolidate the beds and banks of streams, provide food for other organisms and serve to fertilize deposits wherever plant detritus accumulates. For these reasons, $\mathrm{Mr}$ Robson maintains that total eradication of water weeds is seldom desirable, and that partial control by removal of some plants but not others, or temporary suppression of all plant growth at certain periods of the year, are usually more acceptable.

Most methods have drawbacks and, as Mr Robson points out, the possible adverse effects of, for example, herbicides on humans, fish and farm animals must always be carefully considered. Physical removal of weeds is probably the commonest method of control, and for this purpose boats fitted with either $V$-shaped cutters or reciprocating cutter-bars are used. A mowing machine has been introduced from the United States but has not been used to any great extent in Britain so far. Raking or "clotting" is a slow and expensive task and one which Mr Robson maintains is used only as a last resort. Dredging is also unsatisfactory because it does not eliminate the roots and underground parts of weeds, so that plants rapidly re-establish themselves. Experience of burning weeds on the banks of watercourses is limited, but Mr Robson points out that in some situations it may be possible to burn plants killed by herbicides.

Although biological control would seem to be a desirable method of controlling water weeds, it has not been used very widely. As indicated in the bulletin, however, the Ministry of Agriculture, Fisheries and Food recently began an investigation into the possible value of a fish-the Chinese grass carp-in this connexion. 
But of all control methods, herbicides have the brightest future. Among those listed by Mr Robson as having been cleared under the Pesticides Safety Precaution Scheme are 'Dalapon', which is especially active against reeds and other grass-like weeds on river banks; 'Diquat', which is active against submerged weeds; and maleic anhydride, which inhibits plant growth without actually killing the plants.

\section{Comprehensive Planning}

"GoING comprehensive" raises considerable building problems. Following up the Department of Education and Science comment (circular 10/65) that the "disposition, character and size of existing schools" must be taken into account when the change is made, the Architects' Department at the DES has devoted its latest bulletin to the problems, architectural and educational, involved in such a change (Comprehensive Schools from Existing Buildings, Building Bulletin 40, HMSO, 16s.).

The bulk of the bulletin is taken up with five case studies which cover the possibilities of amalgamation of two or more schools with some new buildings, the enlargement of schools of different sizes, and the first stage of a new school which, until further building is possible, uses some old buildings on a different site. The bulletin also briefly rehearses various problems of organization of pupils into groups; accommodation for pupils, administration, and staff; sites; and circulation and storage space. Considerable emphasis is laid on the importance of examining all the possibilities in detail, even though some of them may eventually be rejected. This preliminary section covers a lot of ground but is necessarily short on detail.

As well as suggestions to architects about possible alternative uses for space, there is a plea for the educators to give clear guidance to architects on future teaching requirements. The document stresss that the problem of working accommodation has to be examined as a whole and cannot merely be a sum of the requirements of the individual teachers. Compromise is inevitable, and it is up to the staff, knowing the limitations of time and supply of teachers, to work out a balanced curriculum before sensible accommodation schedules can be produced. If, as is recommended by the DES, the form of reorganization of secondary education in a particular area is to depend on the suitability of existing schools for amalgamation and adaptation, then local authorities should be aware of the factors involved, and it is hoped that this bulletin will indicate some of the questions which should be asked before reorganization is begun.

\section{Persuading Postgraduates}

LAST week saw yet another of the courses aimed at persuading the academically minded that work in industry is not so bad after all. The course is the third graduate school to be organized by the Science Research Council and the Careers Research and Advisory Centre, and was attended by 100 science and technology PhD students working in the universities. It was held in association with the Manchester Business School at the University of Manchester, and is meant to introduce the $\mathrm{PhD}$ students to the variety of problems existing in industry and administration, and the ways in which they are solved. The organizers hope to do this by using the methods of the business schools-the business game, project work and a case study.

The latest graduate school is the first in the series to be run in association with the Manchester Business School; previous courses have been associated with the London Business School. For this reason the Manchester course has a slightly different emphasis. It relies less on case studies, and has as its central exercise a research project on the implications of the introduction of the electric car. $\mathrm{Mr}$ Alan Pearson, of the Manchester Business School, who is Director of Studies at the graduate school, says the work done on the electric car project by the PhD students may well be worth publishing. 'The course membership also includes 28 science and technology PhDs already working in industry and public service organizations, from whom the organizers hope the students will gain a favourable insight into the industrial situation.

One of the difficulties in holding a course of this kind is to judge how successful it has been in changing what are often firmly fixed prejudices. Some information about this may shortly become available. The London Business School, at a similar course held last year, used a questionnaire to gauge the attitudes tc, industry among the participants both before and after the course. The results of the investigation should help in evaluating the success of the venture.

\section{Risks of Radiation}

THE use of radiation techniques is becoming increasingly common in industry, medicine, research and toaching. But, like other industrial risks, the danger's attached to radiation are subject to legal controls which set acceptable limits. The instruments used to monitor radiation must be accurately calibrated, not because the measurement of radiation needs to be extremely accurate but because it is important that any errors associated with instruments, or any interpretation they require, shall be known. This task of calibration is carried out by the Central Electricity Generating Board Dosemeter Calibration Facility at Berkeley Nuclear Laboratories in Gloucestershire.

The facility was built in 1961, and its primary function is to calibrate the instruments used to monitor radiation at CEGB power stations. The capital costs were high, principally because they included a $400 \mathrm{kV}$ accelerator and a $250 \mathrm{kV} X$-ray set. The facility is run by Mr I. M. G. Thompson and a staff of three, who calibrate nearly 1,000 instruments a year. Arrange. ments are now being made to make the service available to anybody who needs it, for a charge of about $£ 60$ for a complete calibration; already more than 50 instruments a year are calibrated for outside organizations.

The standards and techniques used for calibration for radiological purposes are a little unusual, because the risks of radiation are related to dose in different parts of the body rather than to any fundamental properties of the sources or materials involved. For electromagnetic radiation it is possible to relate dose to the unit known as exposure with only limited accuracy, and only in the range between $20 \mathrm{keV}$ and a few $\mathrm{MeV}$. Accurate estimates are therefore rarely justified, but an approximate upper limit to dose is usually sufficient. For neutrons, there is no simple 